\title{
Moebius Sendromlu Hastada Dental Tedavi: Olgu Sunumu
}

\section{Dental Treatment in Patient with Moebius Syndrome: Case Report \\ Merve CANDAN ${ }^{*}\left[\right.$ (D) , Arife KAPTAN ${ }^{2}$ (D)}

${ }^{1}$ Uzman Diş Hekimi, Özel Dental Klinik, Sivas, Türkiye

${ }^{2}$ Sivas Cumhuriyet Üniversitesi Diş Hekimliği Fakültesi Çocuk Diş Hekimliği Anabilim Dalı, Sivas, Türkiye

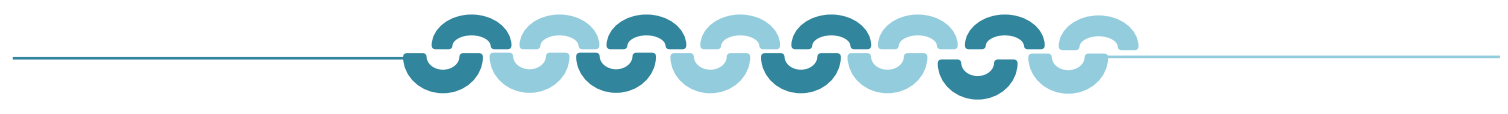

Ö Z E T

Amaç: Kraniyofasiyal anomalilerin sık görüldüğü Moebius sendromunun(MS) insidansı tam olarak bilinmemektedir ve çevresel\&genetik faktörlerin kombinasyonundan kaynaklandığı düşünülmektedir. MS'nin belirti ve semptomlarının çoğu, 6. ve 7. kraniyal sinirlerin yokluğundan veya az gelişmesinden kaynaklanır. Kraniyofasiyal anomaliler de MS'nin öne çlkan semptomları arasındadır. MS'de mikrognati, kısa veya alıșılmadık șekilli dil ve mikrostomi görülebilir. MS'li çocukların dental tedavilerinin genel anestezi altında yapılması gerekebilir. Ancak genel anestezi sırasında dikkat edilmesi gereken bazı durumlar vardır. Bu sendromdan etkilenen bireylerin yaşam kalitesi olumsuz etkilenir ve genellikle özel bakıma ihtiyaç duyarlar. Olgu: Bu olgu sunumu, MS'li bir çocuğun klinik ve dental bulgularını, diş tedavisi sırasında karşılaşılan klinik durumları ve zorlukları ele almaktadır. Sonuç: Moebius sendromlu hastaların değişken oral belirtileri göz önüne alındığında, bu hastaların klinik takibinin diş hekimlerinin de yer aldığı multidisipliner bir yaklaşım gerektirdiği açıktır.

\section{0}

\author{
A B S T R A C T
}

Objective: The incidence of Moebius syndrome (MS), in which craniofacial anomalies are common, is not fully known and is thought to result from a combination of environmental\&genetic factors. Most of the signs and symptoms of MS, are due to the absence or underdevelopment of the 6th and 7th cranial nerves. Craniofacial anomalies are also among the prominent symptoms of MS. Micrognathia, short or unusually shaped tongue and microstomia may seen in MS. Dental treatments of children with MS may need to be done under general anesthesia. However, there are some situations that need to be considered during general anesthesia. The quality of life of individuals affected by this syndrome is negatively affected and they usually need special care. Case: This case report addresses the clinical and dental features of a child with MS and the clinical situations and difficulties encountered during dental treatment. Conclusion: Considering the variable oral symptoms of patients with Moebius syndrome, it is clear that the clinical follow-up of these patients requires a multidisciplinary approach involving dental professionals. 
1. Giriş

Konjenital yüz diplejisi ya da Moebius sekansı olarak da bilinen Moebius sendromunun(MS) insidansı tam olarak bilinmemekle birlikte, 1/50.000-500.000 yenidoğanı etkilediği tahmin edilmektedir. MS'nin olası nedenleri muhtemelen çevresel ve genetik faktörlerin kombinasyonundan kaynaklanmaktadır(1,2). Genetik etiyolojisi, 13q12.2-q13 kromozomunda MBS1, 3q21-q22 kromozomunda MBS2, $10 \mathrm{q} 21$ kromozomunda $M B S 3$ ve 1p22.5 kromozomunda MBS4 olmak üzere dört genetik lokus ile heterojendir(3). Bununla birlikte, subklavyen arter bölgesinde vasküler kesinti, enfeksiyonlar, hipertermi, travma ve benzodiazepinler, talidomid, alkol, kokain ve ergotamin gibi teratojenler de dahil olmak üzere diğer çeşitli etiyolojik faktörler MS için risk faktörleri olabilir(4).

Uni-bilateral konjenital oküler abduksiyonla birlikte konjenital fasial zayıflık olarak tanımlanan MS'de psikomotor ve konuşma gelişimindeki bozukluklar oldukça yaygın olup, hastaların yaklaşık \%10'unda mental retardasyon görülmektedir(1,5,6). Ayrıca, kraniyofasiyal anomaliler de MS'nin belirgin semptomlarındandır. Çeşitli maloklüzyon tipleri, düz alın, düz yanaklar, hipotonik dudak kasları, diş minesinde hipoplazi, dil atrofisi veya hipertrofisi görülebilir. Süt dişlerinin sürme zamanları değişkendir(3). Dental ve oklüzal bozukluklara bağlı olarak, açık kapanış veya derin overbite, maksiller hipoplazi, maksiller darlık, dar ve derin damak kubbesi, mandibular hipoplaziyi içeren çeşitli durumlar gözlenebilir(7). MS'li çocuklarda hem süt hem de kalıcı dişlerde oligodonti, dil felci, mine hipoplazisi, şiddetli biberon çürüğü ve orta-şiddetli diş eti iltihabı görülebilir(8). MS'li bireylerde sağlıklı bireylere nazaran daha fazla çürük görülmekle birlikte, tükürük akış hızı ve tamponlama kapasitesi düşüktür(9). Ayrıca bu bireylerde çürük lezyonları, sendromu olmayan kontrollerden daha erken dönemlerde gözlenmeye başlanır(10). Çeşitli kranial sinirler etkilendiğinden, görüntüleme veya cerrahi işlemler sırasında hastaya anestezi uygulanması gerekebilir(11).

$\mathrm{Bu}$ olgu sunumunda, dış merkezde MS tanısı almış 5 yaşındaki erkek hastanın çocuk diş hekimliği kliniğgine dental ağrı şikayetiyle başvurduğu andaki klinik ve dental bulguları sunulmaktadır.

\section{Olgu Sunumu}

Hastanın velisinden alınan anamnezinden, çocuğun doğumdan itibaren sol göz kapağını tam olarak kapatamama, emme ve işitme fonksiyonunda yetersizlik şikayetleriyle bebeklik döneminde pediatriye başvurdukları ve çocuğun MS tanısı aldığı öğrenilmiştir. Ailenin tek çocuğu olan hastanın ebeveynlerinde herhangi bir sistemik ya da genetik hastalık bulunmamakta olup, ebeveynler arasında akraba evliliği öyküsü yoktur. Hastanın velisinden alınan dental ve medikal anemnezinde hastanın daha önce hiç dental tedavi deneyimi olmadığı, strabismus sebebiyle operasyon geçirdiği, sol kulakta \%90-sağ kulakta \%50 işitme kaybı olduğu ve ağız solunumu yaptığı öğrenildi. Hasta ilk kez 5 yaşında dental ağrı sebebiyle, çocuk diş hekimine başvurmuştur. MS için tipik olan sol taraf yüz kaslarının ifade eksikliği (mimik yetersizliği), sol göz kapağını kapatamama, mikrostomia ve mikrognati hastada mevcuttu. Hasta ayrıca sol kulakta deformasyon, bölgesel saç eksikliği - azlığı, zayıf perioral kaslar ve konuşma bozukluğuna sahipti. Hastanın 2 yaşında yürüdüğü, 5 yaşında ilk kelimelerini söylediği öğrenilmiştir(Şekil 1).

Hastanın zeka geriliği bulunmamaktadır. İntraoral muayenesinde açık kapanış, hipoplastik dil, derin damak, yetersiz oral hijyen ve yaygın-şiddetli diş çürükleri görülmüştür. Fakat klinikte hastayla dental anksiyete ve korkusu sebebiyle kooperasyon kurulamamış, dental radyografi ve intraoral fotoğraf alınamamıştır. Bu sebeple, hastanın dental tedavileri genel anestezi altında gerçekleştirilmiştir.

Hastanın genel anestezi altında ara yüzlerinde çürük bulunan ve mobilitesi olan 51 ve 61 numaralı dişlerin ekstraksiyonu yapıldı. Ayrıca 53,63,73 ve 83 numaralı dişlerin kole\&ara yüzlerindeki çürükler ve $54,64,65,74,75,84$ numaralı dişlerin oklüzal\&ara yüzlerindeki dentin çürükleri restore edildi. Derin dentin çürüklü 85 numaralı dişe amputasyon tedavisi uygulandı. Operasyon sonrası hastaya/velisine oral hijyen eğitimi ve diyet tavsiyesi verilerek, hastanın takibi önerilmiş olup; maalesef hastanın iki yıllık takibi sonucunda 54,64,65,74,84 numaralı dişlerinin arayüzlerinde yeniden çürük oluşumları ve 55 nolu dişte derin dentin çürüğ̈ gözlemlenmiştir.

\section{Tartışma}

MS'de belirti ve semptomlar, doğumdan itibaren mevcuttur. Semptomlarının çoğu, 6. ve 7. kranial sinirlerin yokluğundan veya az gelişmesinden kaynaklanır.

En yaygın bulgularından biri, yüz kaslarının zayıflığı veya felcidir. Etkilenen bireylerin mimikleri yoktur; gülümseyemez, kaşlarını çatamaz veya kaldıramazlar(6). Bozukluk ayrıca konuşma, çiğneme ve yutma 
fonksiyonları için önemli olan diğer kraniyal sinirleri de etkileyebilir(12). MS'li bebeklerde 9. ve 10 . kranial sinir tutulumu sebebiyle, zayıf emme ve yutma koordinasyonuna bağlı beslenme güçlükleri görülebilir. Ayrıca yumuşak damaktaki fonksiyon yetersizliği, dizartri ile sonuçlanabilir(11).

MS'li hastalarda gözlemlenen mikrostomi, mikrognati ve damak yarığı(6), MS'li birçok çocukta var olan konuşma sorunlarını açıklayabilir. Dolayısıyla, hastalarda ă̆ız sağlığının idamesini ve orofasiyal fonksiyonu sağlamak çok önemlidir. MS semptomlarını iyileștirmek için, konuşma terapisti ve pediatrik diş hekimi tarafından erken müdahaleler ve hasta takibi yapılmalıdır(7).

MS göz hareketlerini sağlayan kasları etkilediğinden; göz hareketleri yetersizdir. Bu sebeple, hastalar nesneleri takip edebilmek için başlarını çevirmek zorunda kalırlar ve göz teması kurmakta zorlanırlar(6). Bu durum, dental tedavisi sırasında hastanın kooperasyonunu azaltabilir.

MS'nin diğer özellikleri, el ve ayaklardaki kemik anormallikleri, zayıf kas tonusu (hipotoni) ve işitme kaybıdır. Sendromdan etkilenen çocuklar, çoğu zaman motor becerilerini (örneğin; yürüme) edinebilse de, bu uzun bir zaman alabilir(6). Bu hastaların diş fırçalama kabiliyetleri, motor fonksiyon becerilerinin yetersizliklerinden dolayı zayıf olabilir. Dolayısıyla hastanın velisinden hastanın diş firçalamasına yardımcı olması talep edilebilir.

Şekil 1: Hastanın genel anestezi sırasında alınan sol ve ön cephe fotoğrafları

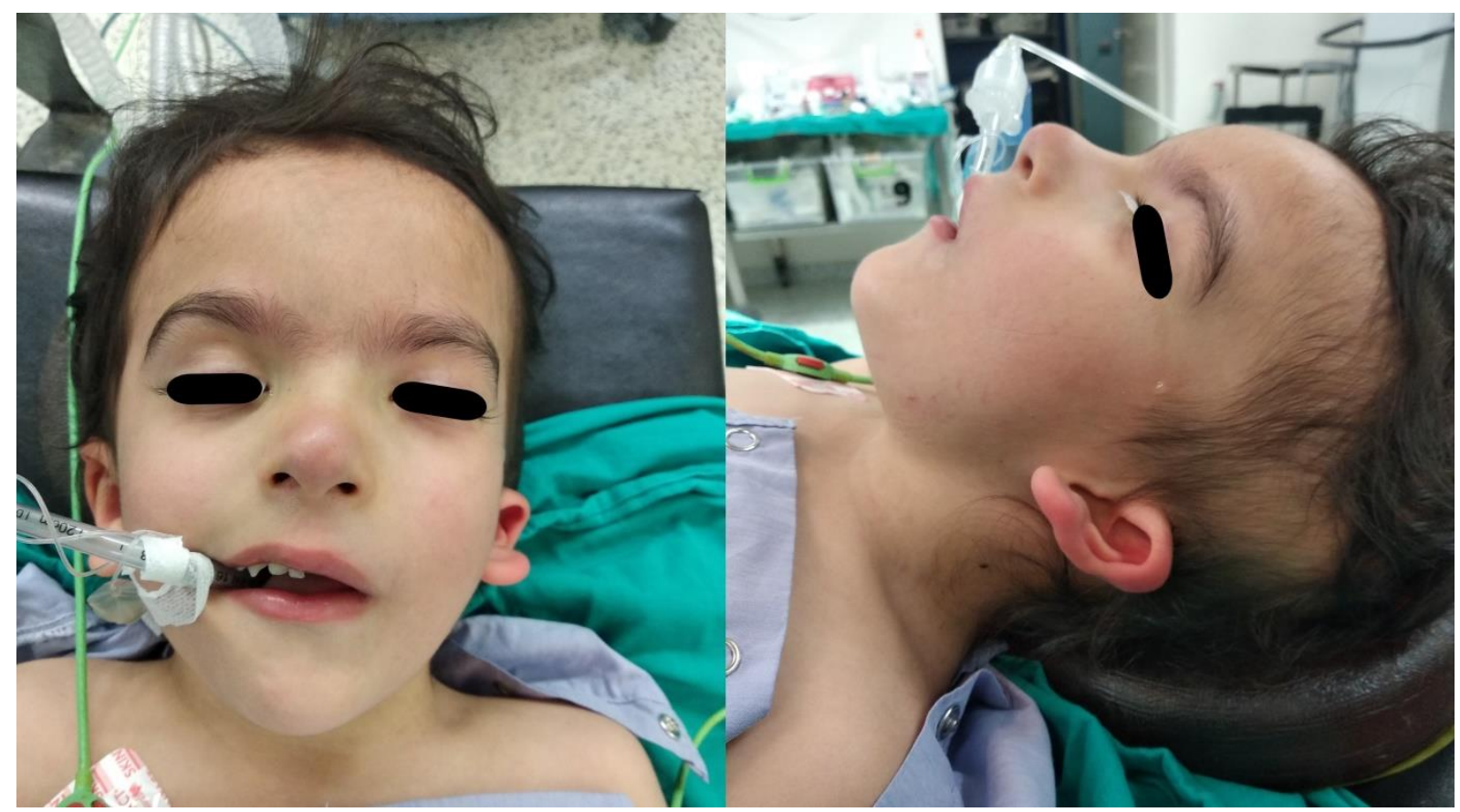

MS bulgularından olan mikrostomia, dental diagnostik muayene ve dental tedavi sırasında kullanılan aletlerin hareket alanını sınırlandırdığından; MS'li hastalarda dental tedavi son derece zor ve zaman alıcı olabilmektedir. Yeterli ağız açıklığının sağlanamadığı durumlarda, mandibular posterior dişlere rejyonel anestezi uygulaması yapılamayabilir(13). MS'li hastaların dil hareketlerindeki anormallikler sebebiyle, dilin temizleme etkinliği yetersiz kalabilir. Ayrıca hastalar dişlerinin lingual veya palatal yüzeylerini fırçalamada yetersiz kalabilir ve rutin diş bakımını gerçekleştiremeyebilirler. Böylelikle dişlerde dental plak birikimi görülebilir. Bu durum, diş çürüklerine ve gingivitise sebep olabilir. Hastalarda yetersiz beslenme, kronik periodontal hastalık ve diş çürükleri yaygındır. Sık diş fırçalama ve diş ipi kullanımı ile yapılan etkili oral hijyen, yiyeceklerin birikmesini önlerken, diş ve diş etlerini korumaya yardımcı olacaktır(12). Ayrıca MS'li hastalarda görülen mikrognati, ortodontik tedavi ihtiyacı doğurmaktadır.

Palatofaringeal disfonksiyon, oral salgıların birikme eğilimi ile kusurlu yutma ve glotisin kötü spazmodik kapanması sebebiyle, hava yolu açıklığının korunamaması gibi durumlar oluşabilir ve hastalar tekrarlayan aspirasyon problemleri yaşayabilirler(11). Dental tedavi sırasında ağızda biriken su ve tükrük sebebiyle, aspirasyon riski artabilir. Bu sebeple, MS'li hastaların dental tedavileri sırasında yüksek emiş gücüne sahip tükrük emiciler kullanılmalıdır. Tüm bu durumlar göz önüne alındığında, MS'li çocukların dental tedavilerinin genel anestezi altında yapılması gerekebilir. Ancak genel anestezi uygulaması sırasında dikkat edilmesi gereken bazı durumlar mevcuttur. MS ile ilişkili hipoplastik dil, mikrognati, mikrostomi, yarık damak, bifid uvula gibi anatomik yapılar veya ağız açıklığı kısıtlılığı genel anestezi sırasında hem 
maske ventilasyonunu, hem de doğrudan laringoskopi yoluyla endotrakeal entübasyon açısından rutin hava yolu yönetimini sorunlu hale getirebilir(11). MS'li hastaların genel anestezi uygulaması öncesi bu hastalarda karşılaşllabilecek entübasyon zorluğu öncelikle göz önünde bulundurulmalıdır. Ayrıca miyopatik bozuklukları olan hastalarda olduğu gibi, MS'li hastalarda da süksinilkolin kullanımından kaçınılması gereklidir. Hipotoni ayrıca hem üst hava yolu, hem de torasik kas ve diyafram düzeyinde postoperatif solunum fonksiyonunu etkileyebilir. Bu nedenle, MS'li hastalarda genel anestezi uygulaması sonrası postoperatif solunum fonksiyonunun sürekli izlenmesi ve kısa klinik etkiye sahip anestezik ajanlar tercih edilmesi önerilmektedir(11).

\section{Sonuç}

Sonuç olarak MS, klinik olarak bir grup kranial sinirin felci ile karakterize nadir görülen konjenital bir durumdur. Sendrom etkilenen bireylerin yaşam kalitesi üzerinde olumsuz sonuçlar oluşturabilir ve etkilenen çocuklar genellikle özel bakıma ihtiyaç duyarlar. Bu makale MS sendromlu bir çocuğun dental\&klinik durumunu sunmaktadır ve diş tedavisi sırasında karşılașllabilecek klinik durumları ve zorlukları ele almaktadır. MS'nin etyopatolojik yönleri ve klinik belirtileri hakkında bilgi sunmak, bu bireylerin ve ailelerinin yaşam kalitesini iyileștirmeyi amaçlayan tedavileri mükemmelleștirmek için gereklidir. Sendromun değişken oral belirtileri göz önüne alındığında, diș hekimliğinin MS’li bireylerin bakımında temel bir rol oynadığı açıktır. Klinik bulguların geniș ve değișken spektrumu nedeniyle, bu hastalar için standart bir tedavi ve anestezi planı önerilemez. Dolayısıyla, MS'li hastalarda koruyucu\&önleyici diş hekimliği uygulamaları ve oral hijyen alışkanlıklarını oluşturabilmek çok önemlidir. Böylelikle, ilerleyen dönemde daha zorlu tedavileri gerektiren durumların önüne geçilmiş olur. MS'li hastanın bulgularına spesifik bir tedavi planı oluşturmak, bu hastaların tedavilerinde yer alan hekimlerin sorumlulukları arasında yer alır. Bu sebeple, MS'li hastaların değişken oral belirtileri göz önüne alındığında, bu hastaların klinik takibinin diş hekimlerinin de yer aldığı multidisipliner bir yaklaşım gerektirdiği açıktır.

\section{Kaynakça}

[1] Briegel W, Schimek M, Kamp-Becker I. Moebius sequence and autism spectrum disorders--less frequently associated than formerly thought. Res Dev Disabil. 2010;31(6):1462-6.

[2] Albayrak HM, Tarakçı N, Altunhan H, Örs R, Çaksen H. A congenital cranial dysinnervation disorder: Möbius' syndrome. Turk Pediatri Ars . 2017;52(3):165-8.

[3] Bartzela TN, Carels C, Maltha JC. Update on 13 Syndromes Affecting Craniofacial and Dental Structures. Front Physiol. 2017; 8: 1038. Doi: 10.3389/fphys.2017.01038

[4] Ghosh R, Shetty V, Hegde S, Babu GS, Ajila V, Kishore P N, vd. Rare features associated with Mobius syndrome: Report of two cases. J Dent Res Dent Clin Dent Prospects. 2017;11(1):60-5.

[5] Briegel W, Schimek M, Knapp D, Holderbach R, Wenzel P, Knapp E-M. Cognitive evaluation in children and adolescents with Möbius sequence. Child Care Health Dev. 2009;35(5):650-5.

[6] Moebius syndrome. Genetics Home Reference. Erişim tarihi: 27 Şubat 2020. Erişim adresi: https://ghr.nlm.nih.gov/condition/moebius-syndrome

[7] Sjögreen L, Andersson-Norinder J, Jacobsson C. Development of speech, feeding, eating, and facial expression in Möbius sequence. Int J Pediatr Otorhinolaryngol. 2001;60(3):197-204.

[8] De Serpa Pinto MV, De Magalhães MH, Nunes FD. Moebius syndrome with oral involvement. International Journal of Paediatric Dentistry. 2002;12(6):446-9.

[9] Martins Mussi MC, Moffa E, Castro T, Lira Ortega A, Freitas G, Braga M, vd. Salivary parameters and oral health in the Moebius syndrome. Spec Care Dentist. 2016;36(5):265-70.

[10] Castro T, Ortega AOL, Mussi MC, Braga MM, Gallottini M. Caries Experience in Individuals with Moebius Syndrome. Pediatr Dent. 2016;38(1):68-71.

[11] Gondipalli P, Tobias JD. Anesthetic implications of Möbius syndrome. J Clin Anesth. 2006;18(1):55-9.

[12] Moebius syndrome. Children's Craniofacial Association. Erişim tarihi: 27 Şubat 2020. Erişim adresi: https://ccakids.org/moebius-syndrome.html

[13] Nussbaum BL. Dental care for patients who are unable to open their mouths. Dent Clin North Am. 2009;53(2):323-8, x. 